\title{
BUCKLING LOAD ANALYSIS OF A HYDRAULIC CYLINDER
}

\author{
Ramasamy.V ${ }^{1}$, Junaid Basha.A.M ${ }^{2}$ \\ ${ }^{1}$ Sundaram Hydraulics Ltd, Chennai, India \\ ${ }^{2}$ C.V.R.D.E, Chennai, India \\ Email: ${ }^{1}$ rmvram@sify.com
}

\section{Abstract}

The buckling load is an important parameter necessary for designing a hydraulic cylinder. There are several methods available to analyse the buckling load of a hydraulic cylinder. In the present work for a typical cylinder, critical buckling load has been analysed using Energy method, ANSI-NFPA Hoblit method and FEA. The specified hydraulic cylinder has been subjected to buckling load test on a specially designed test rig. The results and conclusion are presented.

Key words: Hydraulic cylinder, Buckling, Critical load, Energy method, Hoblit method, Telescopic cylinder.

\section{Nomenclature}

P Critical buckling load, N

$\mathrm{E}_{1} \quad$ Young's modulus of rod, $\mathrm{N} / \mathrm{m}^{2}$

$E_{2} \quad$ Young's modulus of tube, $\mathrm{N} / \mathrm{m}^{2}$

$\mathrm{l}_{1} \quad$ Moment of inertia of rod, $\mathrm{m}^{4}$

$\mathrm{I}_{2}$ Moment of inertia of tube, $\mathrm{m}^{4}$

M Bending moment, $\mathrm{Nm}$

y Deflection, $\mathrm{m}$

$\mathrm{L} \quad$ Cylinder open length, $\mathrm{m}$

$L_{1} \quad$ Cylinder rod length, $m$

$\mathrm{L}_{2} \quad$ Cylinder tube length, $\mathrm{m}$

$\mathrm{U} \quad$ Strain energy, $\mathrm{Nm}$

$\mathrm{T} \quad$ Work done by compressive force, $\mathrm{Nm}$

$d_{1} \quad$ Rod inner diameter, $m$

$D_{1} \quad$ Rod outer diameter, $m$

$d_{2}$ Tube inner diameter, $m$

$D_{2} \quad$ Tube outer diameter, $m$

$\sigma \quad$ Critical buckling stress $\mathrm{N} / \mathrm{m}^{2}$

\section{INTRODUCTION}

The telescopic hydraulic cylinders with stroke length up to 40 meter and lifting capacity higher than 2000 tons are used extensively in construction and earthmoving industries, cranes, dam gate hoist, drill rigs, material handling equipments.
The hydraulic cylinders are normally classified based on the mounting and geometric boundary conditions as given in the following.

1. Trunnion / Clevis and Rod eye mounting (both ends hinged / pinned)

2. Flange / Foot lug \& Rod eye mounting (fixed and hinged / pinned)

3. Flange \& Rod mounted to floating structure (fixed and free)

While designing the telescopic hydraulic cylinders care has to be taken to analyse the critical buckling load. The ISO TS 13725 method [1] is used for calculating the buckling load of single stage cylinders with different mounting conditions. The main disadvantage of this method is that, it cannot be used for multi stage cylinders. The ANSI - NFPA Hoblit method [2] describes the method for calculating the single stage hydraulic cylinder with both ends hinged mounting condition. The main drawback of this method is that it cannot be used for cylinders with other mounting conditions. However the energy method [3] can be used for calculating the buckling load of hydraulic cylinders with different mounting conditions by suitably modifying the deflection equation.

The present work describes the analysis of hydraulic cylinders for critical buckling load using Energy method, ANSI-NFPA Hoblit method and FEA with both ends hinged mounting condition. For the initial case study some of the imperfections related to the cylinder and its loading conditions are not considered in the present analysis. 


\section{CRITICAL BUCKLING LOAD}

The critical buckling load (Euler load) of a hydraulic cylinder considered as an axially loaded compressed column is defined as the axial load necessary to keep the bar in a slightly bent form. The critical buckling load actually marks the transition point from where the compressed column undergoes from stable to unstable equilibrium. The Fig. 1 indicates the stable, neutral and unstable equilibrium [4].
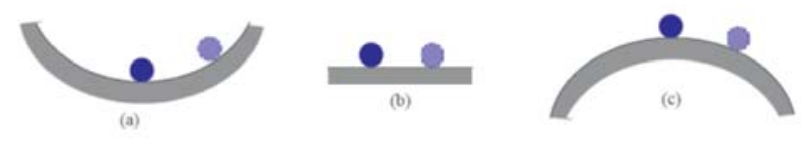

Fig. 1. Three states of equilibrium

When the applied load is less than the critical buckling load, the column remains straight and a small deflection is produced. The deflection disappears when the load is removed. The straight (or) slightly bent form of column is said to be in stable equilibrium. If the load is gradually increased, a condition is reached in which the straight form of equilibrium becomes unstable and the deflections does not disappear when the load is removed. The Fig. 2 shows the load displacement curve of buckled column [5].

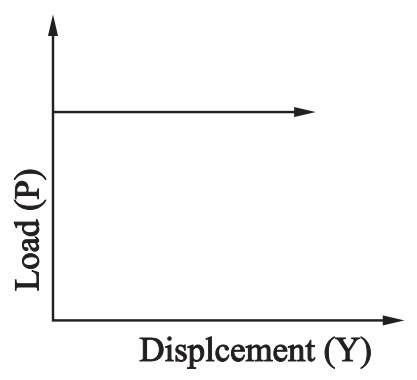

Fig. 2. Load-displacement curve

The critical Stress is defined as the ratio of critical buckling load to the area of the cross section as given below.

$$
\sigma=P / A
$$

The critical buckling load (Euler Load) for both ends hinged column as shown in Fig. 3 is given in the following Eqn. (2).

$$
P=\frac{n^{2} \pi^{2} E l}{L^{2}}
$$

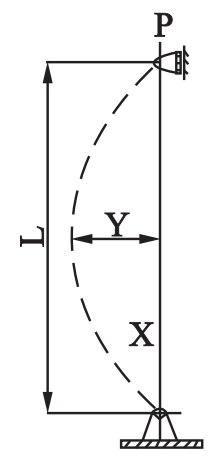

Fig. 3. Euler column

The smallest eigen value when $n=1$ gives the critical buckling load and the corresponding eigen vector gives the buckling modes shapes [3] as shown in Fig 4.

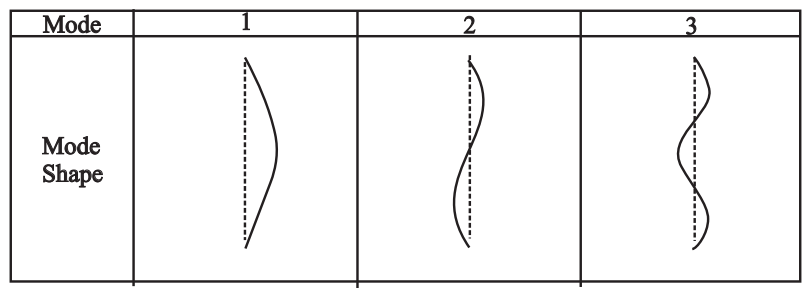

Fig. 4. Buckling mode shape

The critical load of hydraulic cylinders with longer strokes are calculated using the Hoblit method [2], Finite element displacement method [6], Strain energy method [3] and other general computational methods. Normally for the analysis, the cylinders are considered as a slender stepped non-prismatic column subjected to buckling load without any transverse load and the geometric imperfections. The following Euler Bernoulli's assumptions are considered in the analysis.

- Material is homogeneous and isotropic

* Plane sections remain plane after loading

* The stress- strain curve is identical in both tension and compression

* No local buckling (or) instability will occur

* The effect of transverse shear is negligible and hook's law holds 
* Deflections are very small compared to cross sectional dimensions

- Load is static

The main advantage of calculating critical buckling load by the above methods for the hydraulic cylinders is to predict the failure of piston rods by buckling and failure of wear ring / bearings of cylinder piston and glands. This is applicable only to long stroke hydraulic cylinders and cannot be used for short stroke cylinders.

\section{ENERGY METHOD}

In the energy method, the critical buckling load for the cylinder is analysed considering the potential energy required to reduce the column length by a small amount $x$ under the compressive force $\mathrm{P}$ as shown in Fig.3. The potential energy for buckling the column is given by [3].

$$
\Delta T=\frac{1}{2} P \times x
$$

Where, displacement $x=\frac{P L}{A E}$

Then, $\Delta T=\frac{P^{2} L}{2 A E}$

Whereas the strain energy required for bending of the column during buckling is given by [3].

$$
\Delta U=\frac{P^{2} L}{2 A E}
$$

From equations (4) and (5) it is observed that for a single stage cylinder with one end hinged, the potential energy is equal to the strain energy for the same force and displacement.

In case of the single stage hydraulic cylinder with both ends hinged as shown in Fig.5 the critical buckling load is calculated using Strain energy method [3].

The first approximation for the Deflection curve of the hydraulic cylinder with pinned condition is given by [3].

$$
E I \frac{d^{4} y}{d x^{3}}+P \frac{d^{2} y}{d x^{2}}=0
$$

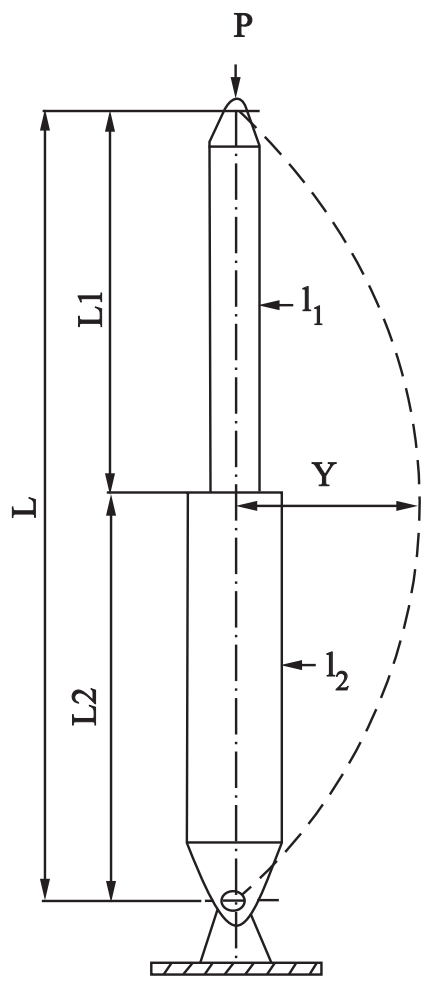

Fig. 5. Hydraulic cylinder single stage

$$
\frac{d^{4} y}{d x^{4}}+k^{2} \frac{d^{2} y}{d x^{2}}=0
$$

where, $k^{2}=P / E I$

The general solution of the above equation is

$$
y=A \sin (k x)+B \cos (k x)+C x+D
$$

$A, B, C \& D$ are constants of integration and can be found out from the boundary conditions as given below. The deflection and bending moment are Zero at ends, $x=0 \& x=L$.

$$
y=\frac{d^{2} y}{d x^{2}}=0, \text { at } x=0 \text { and } x=L
$$

Applying these conditions to the general equation we get,

$$
\begin{gathered}
B=C=D=0, \\
\sin (k L)=0
\end{gathered}
$$

Hence, $k L=n$, where $n=1$ for lowest critical load. 
Therefore, $y=A \sin (p i x / L)$

With $k L=\pi$

Bending moment, $M=P y$

Strain energy of bending, $\Delta U=$ Work done by compressive forces $P$ during buckling, $\Delta T$

$\Delta U=\int_{0}^{L^{2}} M^{2} d x / 2 E_{2} I_{2}+\int_{L 2}^{L} M^{2} d x 23_{1} I_{1}$

Substituting, $M^{2}=P^{2} A^{2} \sin ^{2} \pi X / L$ modulus,

and assuming tube and rod having same young's

$$
E_{1}=E_{2}=E
$$

We get,

$$
\begin{gathered}
\Delta U=\int_{0}^{L 2} \frac{P^{2} A^{2} \sin ^{2} \pi x / L}{2 E I_{2}} d x \\
+\int_{L 2}^{L} \frac{P^{2} A^{2} \sin ^{2} \pi x / L}{2 E I_{2}} d x \\
\quad=\frac{P^{2} A^{2}}{2 E l_{2}}\left\{\frac{L_{2}}{2}-\frac{L}{4 \pi} \sin \left(2 \pi L_{2} / L\right)\right\} \\
+\frac{P^{2} A^{2}}{2 E I_{1}}\left\{\frac{L_{1}}{2}+\frac{L}{4 \pi} \sin \left(2 \pi L_{2} / L\right)\right\}
\end{gathered}
$$

The work done is given by,

$$
\Delta T=P \int_{0}^{L} \frac{1}{2}\left(\frac{d y}{d x}\right)^{2} d x
$$

where

$$
\frac{d y}{d x}=A \pi / L \cos (\pi x / L)
$$

$$
\Delta T=\frac{P A^{2} \pi^{2}}{2 L^{2}} \int_{0}^{L}\left\{\frac{1}{2}+\left(\frac{\cos \left(\frac{2 \pi x}{L}\right)}{2}\right)\right\} d x
$$

Solving the above, $\Delta T=\frac{P A^{2} \pi^{2}}{4 L}$

Equating $\Delta U \& D E L T a T$, we get,

$P=\frac{\pi^{2} E I_{2}}{L^{2}}\left\{\frac{L_{2}}{L}+\frac{l_{2} L_{1}}{l_{1} L}+\frac{1}{2 \pi} \sin \left(\frac{2 \pi L_{2}}{L}\right)\left[\frac{l_{2}}{l_{1}}-1\right]\right\}$

As a case study, the buckling load of a typical hydraulic cylinder is calculated using Eqn. (14) with the followingpecifications,

Cylinder specifications

$$
\begin{aligned}
d_{1} & =0 \\
d_{2} & =0.07 \mathrm{~m} \\
D_{1} & =0.04 \mathrm{~m} \\
D_{2} & =0.082 \mathrm{~m} \\
L_{1} & =0.885 \mathrm{~m} \\
L_{2} & =0.975 \mathrm{~m} \\
L & =L 1+L 2 \\
& =1.86 \mathrm{~m}
\end{aligned}
$$

$$
\begin{aligned}
E_{1} & =E_{2}=E=2.05 \times 10^{11} \mathrm{~N} / \mathrm{m}^{2} \\
I_{1} & =\pi\left(D_{1}^{4}-d_{1}^{4}\right) 64 \\
& ==125664 \times 10^{-12} \mathrm{~m}^{3} \\
I_{2} & =\pi\left(D_{2}^{4}-d_{2}^{4}\right) 64 \\
& =1040762 \times 10^{-12} \mathrm{~m}^{3}
\end{aligned}
$$

Substituting the above values in Eqn. (14), the critical buckling load by strain energy method is obtained as $P=141902 \mathrm{~N}$

\section{ANSI / (NFPA) T3.6.37-1991 METHOD}

The standard developed by the National Fluid Power Association Inc USA and American National Standards Institute uses the Hoblit method known as ANSI /(NFPA) T3.6.37-1991 method [2] for calculating the critical buckling load. This method is limited only to pin mounted hydraulic cylinders and is not applicable 
for other type of mounting conditions. The main drawback of this method is that it cannot be used for cylinders with flange / trunnion mountings and multistage cylinders.

Using the above ANSI method the critical buckling load for the specified single stage hydraulic cylinder with both ends hinged as shown in Fig.5 has been obtained as $\mathrm{P}=129367 \mathrm{~N}$

\section{ANSYS - FINITE ELEMENT ANALYSIS METHOD}

The specified hydraulic cylinder as given in section III and shown as model in Fig. 6 has been analysed by finite element method using ANSYS software to verify the critical buckling load calculated by energy method.

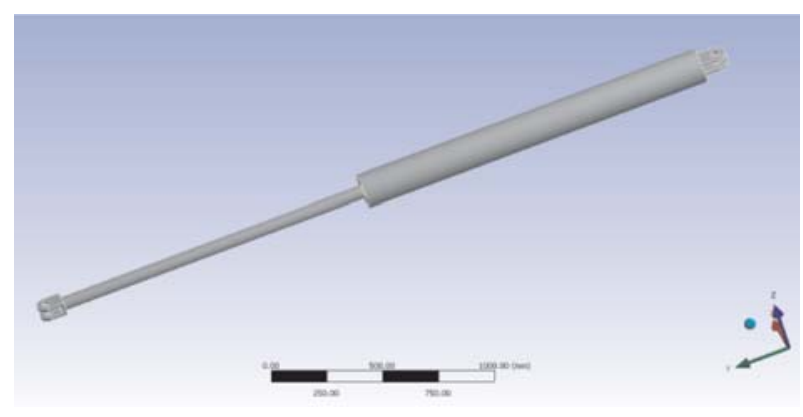

Fig. 6. Hydraulic cylinder model

Using the following parameters and boundary conditions, the hydraulic cylinder mesh and mode shapes are shown in Fig.7 to Fig. 9.

\section{A. FEM parameters}

Element size $=5 \mathrm{~mm}$

Element type $=$ Beam 188

Load applied $=141902 \mathrm{~N}$

B. Boundary conditions

(a) Rear clevis end

1. Deflection in three axis $x, y \& z$ fixed

2. Rotation in $x \& z-$ axis fixed

3. Rotation in y axis free (b) Front rod end

1. Deflection in Two axis $y \& z$ fixed

2. Rotation in $x \& z$ axis fixed

3. Rotation in $y$ axis free

4. Deflection in $x$ axis free

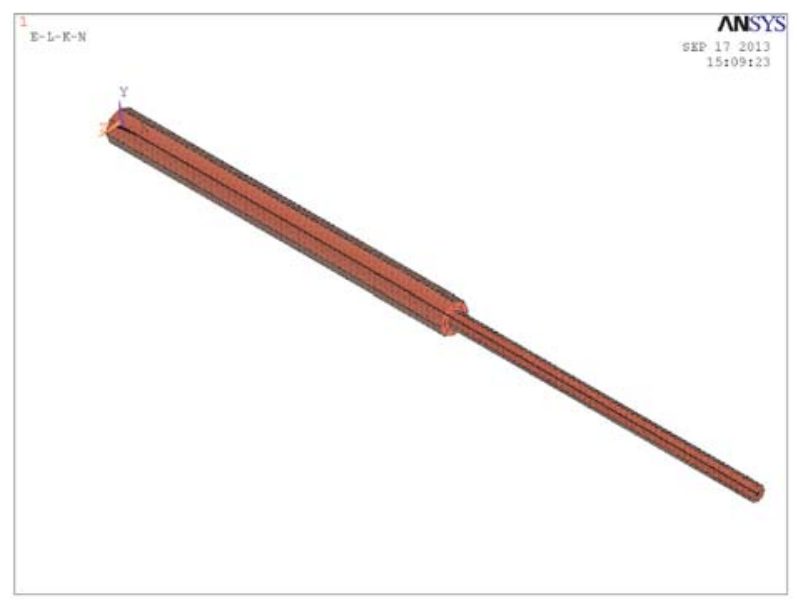

Fig. 7. Hydraulic cylinder mesh

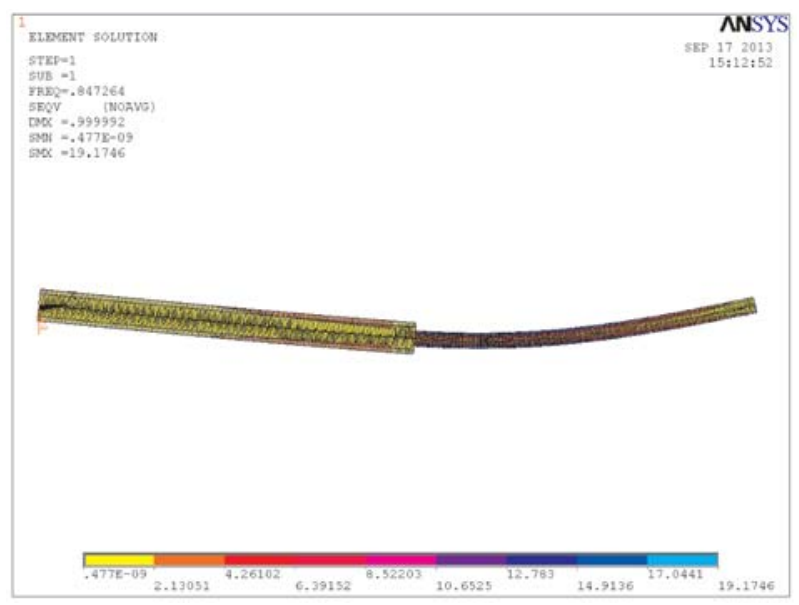

Fig. 8. Mode shape 1

The lowest critical buckling load corresponding to eigen value of mode shape 1 is $P=120228 \mathrm{~N}$

The critical buckling load corresponding to eigen value of mode shape 2 is $P=573953 \mathrm{~N}$ 


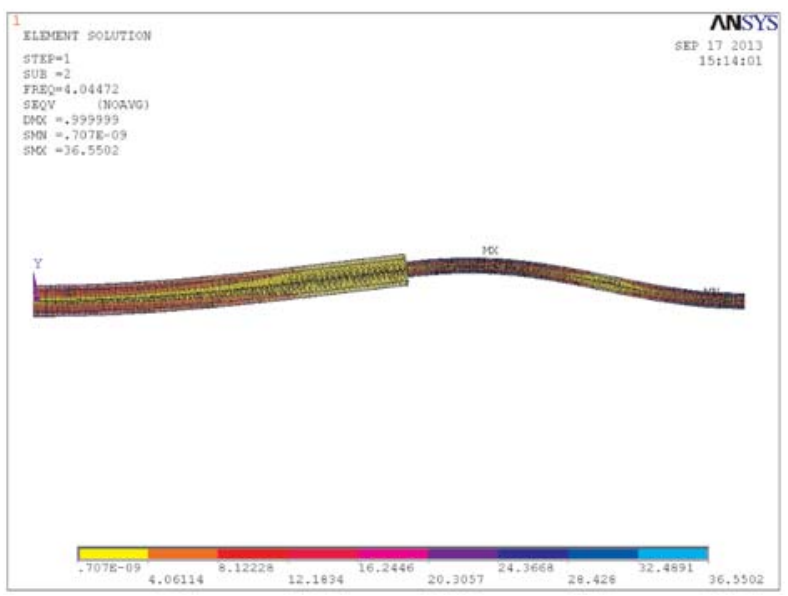

Fig. 9. Mode Shape 2

\section{BUCKLING LOAD TEST}

The specified cylinder as given in section III has been subjected to buckling load test. The test bench and the test procedure are described in the following.

\section{A. Buckling load test bench}

The load test bench consists of mechanical structure having two platens connected by four tie rods as shown in Fig.10. The master cylinder of capacity 80 tons is mounted on one end of the platen and rod end of the master cylinder is connected with the rod end of test cylinder. The test cylinder rear end is mounted on the other platen. The test cylinder is connected to the hydraulic system as shown in Fig.11.

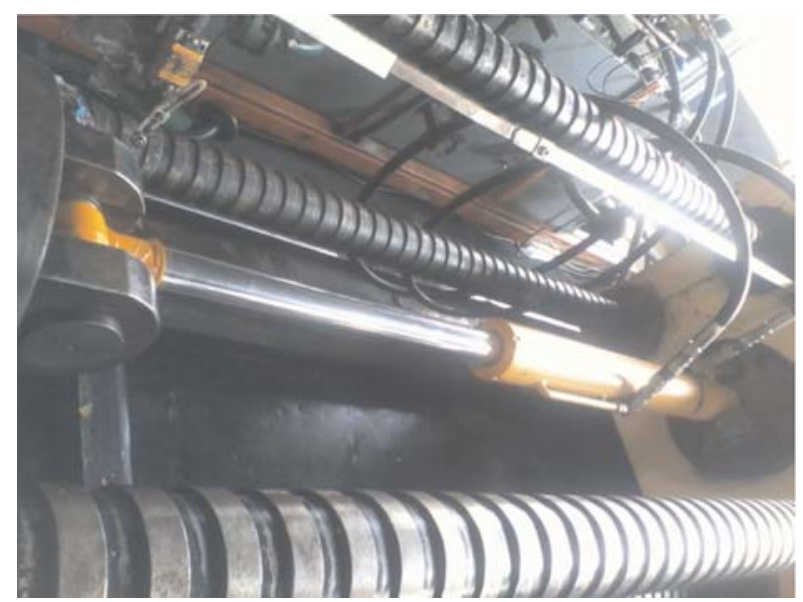

Fig. 10. Hydraulic cylinder load test bench

The hydraulic power pack is operated by an electrical control system. The master cylinder is connected to load holding check valve (4.2) and port relief valve (6.1). The master cylinder gives the resistance load set in the port relief valve (6.1). The port relief valve (6.1) pressure is set higher than the buckling load of test cylinder. The oil pressure is applied to the test cylinder against the resistance of master cylinder load till it buckles. The buckling load is arrived from the pressure at which the cylinder buckles by multiplying the test cylinder bore area. The frictional loss due to seals is negligible compared to the load pressure.

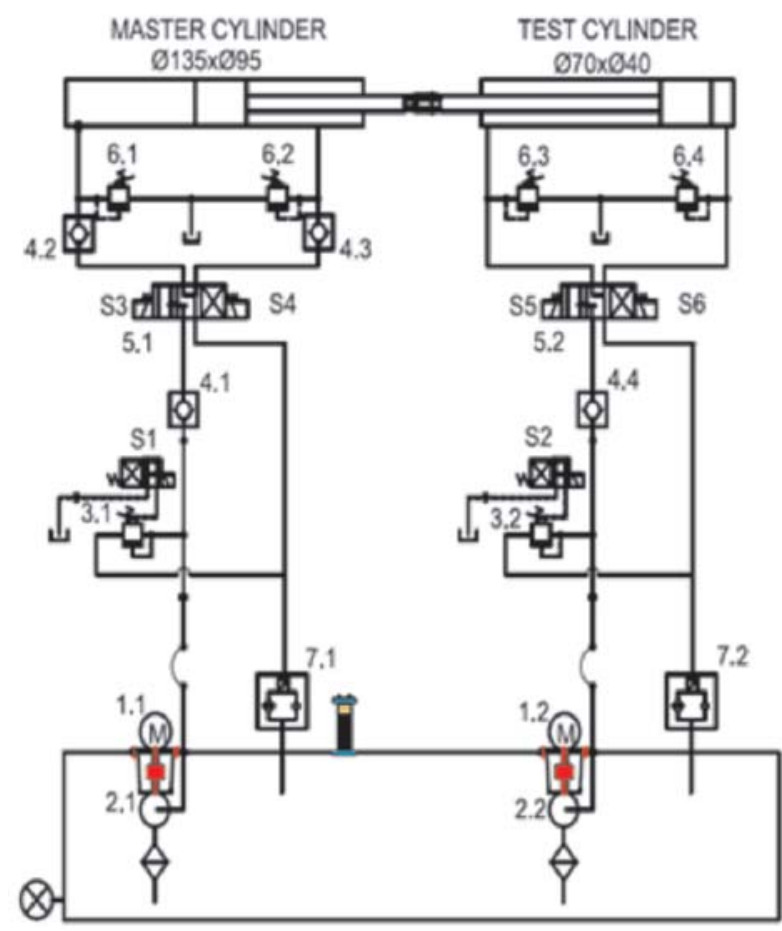

Fig. 11. Hydraulic circuit of load test bench

With the above test facility, the specified test cylinder of bore area $70 \mathrm{~mm}$ and rod diameter of $40 \mathrm{~mm}$ with fully extended length of $1860 \mathrm{~mm}$ buckles at a pressure of 380 bar. Therefore the buckling load has been obtained as $146762 \mathrm{~N}$.

\section{RESULTS AND DISCUSSIONS}

The comparative results of the critical buckling load obtained for the specified hydraulic cylinder with different methods and the test bench are presented in Table 1. The critical buckling load obtained through strain energy method compares closely with the test bench result. Whereas the FEA results show lower critical buckling load since the seal frictional force in the cylinder and other imperfections are not considered in the analysis. 
Table 1. Comparative results of buckling load analysis

The ANSI NFPA Hoblit method show a lower buckling load due to approximations in the analysis. The strain energy method can be used with certain modifications in the Eqn. [9] for obtaining critical buckling load for a three stage telescopic hydraulic cylinder widely used in the material handling equipments.

Table 1 Comparative results of buckling load analysis

\begin{tabular}{|l|c|}
\hline \multicolumn{1}{|c|}{ Method } & $\begin{array}{c}\text { Critical buckling } \\
\text { load in N }\end{array}$ \\
\hline Strain energy method & 141902 \\
\hline ANSI + NFPA Hoblitz method & 129367 \\
\hline $\begin{array}{l}\text { Finite element analysis } \\
\text {-ANSYS }\end{array}$ & 120228 \\
\hline Buckling load on test bench & 146762 \\
\hline
\end{tabular}

\section{CONCLUSION}

The critical buckling load is an important factor required for designing a long telescopic hydraulic cylinder. For a specified single stage hydraulic cylinder different methods have been used for analysing the buckling load. The specified cylinder has been subjected to buckling load test on a test bench. The test results are compared with the analytical results. The strain energy method leads to a simple solution with critical buckling load closely compare to the test results. Although the FEA results are comparatively lower than the test results, it can be refined by considering the imperfections of the hydraulic cylinders. The critical buckling load obtained through ANSI NFPA Hoblit is not close to the test results. Therefore the strain energy method provides the critical buckling load with reasonable accuracy in less time and effort compared to the available methods. The strain energy method can be extended to analyse the critical buckling load of three stage hydraulic cylinders with suitable modifications.

\section{REFERENCES}

[1] ISO TS13725, 2001, Method of determining the buckling load, hydraulic fluid power-cylinders

[2] ANSI / (NFPA) T3.6.37, 1998, Method of determining the buckling load, hydraulic fluid power - cylinders

[3] Timoshenko \& Gere, 1936, Theory of elastic stability, McGraw hill publication.

[4] Alexander Chages, 1974, Principles of structural stability theory, Prentice-Hall Inc.

[5] lyengar N.G.R., 1986, Structural stability of columns and plates, Affiliated east west press.

[6] Chai Hong Yoo \& Charles Siegel R., 1984, Column loadings on telescopic power cylinders, Auburn University USA. 